Leading Article

\title{
Scrotal pain
}

\author{
R.J. Morgan and J.R.W. Parry
}

Department of Urology, The Whittington Hospital, Highgate Hill, London N19 5NF, UK.

Scrotal pain is a common and worrying symptom for which an adequate explanation cannot always be found. In this issue of the Postgraduate Medical Journal Dr Watanakunakorn ${ }^{1}$ adds to the long list of possible causes of this form of pain.

The nerve supply of the scrotum and its contents is derived from disparate parts of the nervous system. Within the scrotum, the testis, vas and epididymis appear to be innervated by sympathetic fibres from T1-T12 and T1-L1 respectively, whilst the outer surface of the testis, the tunica vaginalis and the anterior scrotal skin receive somatic fibres from L1L2. The rest of the scrotal skin is innervated by somatic branches of S2-S3. Pain felt in the scrotum may therefore be referred from visceral or somatic structures with the same segmental nerve supply. Thus a stone impacted in the lower ureter, with a splanchnic L1 innervation, may cause scrotal pain in this way, as may compression of the genitofemoral nerve by a small inguinal hernia, or, exceptionally, an aneurysm of the internal iliac artery. Degenerative lesions of the spine and, rarely, inflammatory or neoplastic disease of genital viscera may cause a similar referred pain. Pain which is generated by some change within the scrotum itself usually stimulates somatic as well as autonomic fibres and is therefore accurately localized to the scrotum.

Cystic swellings of the scrotum rarely cause pain, although a very large hydrocele may cause discomfort by dragging on the cord or by distension of the tunica vaginalis. Should bleeding occur in a hydrocele or in an epididymal cyst or should they become infected, commonly after needle aspiration, then both may become acutely painful. Varicoceles are usually painless swellings, but exceptionally large ones can ache after exercise or after long periods of standing. Patients occasionally present with acute pain as a result of thrombosis within the varicocity. Such pain is often encountered after high ligation or embolization of a varicocele and patients who undergo such

Correspondence: R.J. Morgan FRCS

Received: 26 February 1987 procedures should be warned of the possibility of such pain thereafter.

Testicular torsion commonly presents with acute pain accompanied by swelling and redness of the scrotum in children or young adults. However, Chapman \& Walton ${ }^{2}$ in their study based at the London Hospital, showed that $44 \%$ of patients with testicular torsion initially presented with recurrent brief episodes of scrotal discomfort. Such 'warning' pains presumably were relieved by the spontaneous untwisting of the cord. It remains imperative that any person suspected of having a testicular torsion should have an emergency surgical exploration of the scrotum. At such an operation the pain and swelling is occasionally found due to a torsion of the appendix testis (pedunculated hydatid of Morgagni). Very occasionally the clinical diagnosis can be made before the operation if the child is seen early enough to allow the doctor to identify a tender swelling localized to the upper pole of the testis. More commonly the scrotum becomes swollen and painful too quickly to permit such discrimination. Spontaneous fat necrosis and ideopathic scrotal oedema are often listed as possible differential diagnoses of testicular torsion in children. These exceptionally rare disorders should only be diagnosed after surgical exploration has taken place.

True orchitis may involve one or both testicles and is seen most commonly in this country in association with mumps. Although not likely to cause long term problems in childhood, such orchitis can cause testicular atrophy in the $15 \%$ of adults with mumps who develop testicular pain and swelling. Draining a secondary hydrocele and incising the tunica albuginea may relieve the pain in extreme cases. Infectious mononucleosis, dengue fever and infection with coxsackie B virus may all occasionally produce an orchitis, whilst rarely an arteritis (Buerger's disease, polyarteritis nodosa, Henoch-Schönlein purpura) may present in this way.

In an adult the commonest cause of acute scrotal pain is epididymal infection. Before the antibiotic era gonorrhoea was regarded as the commonest cause of acute epididymitis, but now infecting organisms are not always easily identified. Mittemeyer et al. ${ }^{3}$ were 
only able to identify a bacterial cause in a quarter of 610 cases occurring in United States soldiers. Most of the organisms which were cultured were coliforms. Although trauma and the spontaneous reflux of urine down the vasa were postulated as causes in those in whom cultures were negative, it is now realised that infection with $\mathrm{D}$ to $\mathrm{K}$ serotypes of Chlamydia trachomatis and more rarely mycoplasma would probably have accounted for the attacks of 'sterile' epididymitis. ${ }^{4}$

The route by which infecting organisms reach the epididymis is uncertain, but such evidence as there is points towards the passage being by lymphatics or by the tissue spaces surrounding the musculature of the vas. Not only can epididymitis occur after a vasectomy but also it seems unlikely that urine can reflux down the vas in a healthy male. A valvular mechanism normally exists at the opening to the ejaculatory ducts and the direction of muscular contraction waves in the vasa, the activity of cilia and the blockage of the ducts by semen would make retrograde urine flow unlikely. Certainly Lapides ${ }^{5}$ found the urethral pressure always exceeded the bladder pressure during straining and no reflux can be demonstrated radiologically during cystography in patients with epididymitis.

If the antibiotic treatment of a bacterial epididymitis is delayed or unsuccessful, the infection can progress to abscess formation with destruction of the epididymis and involvement of the testis. In these circumstances an orchidectomy is usually required. A similar clinical picture to that of acute epididymitis may be seen in cases of spontaneous extravasation of sperms into the epididymis, causing a seminal granuloma with localized pain, tenderness and swelling. Where leakage of sperms occurs at the site of vasectomy similar sperm granulomas may form in the adjacent soft tissues and may persist as locally painful nodules.

Whenever an inflammatory testicular swelling fails to resolve with treatment the possibility of an underlying testicular tumour should always be considered as approximately $10 \%$ of testicular tumours may present with pain and an impression of an inflammatory mass. In such cases of doubt regarding the clinical diagnosis of an intrascrotal swelling the use of scrotal ultrasound can be of great help in determining the nature of the pathological change. The classical ultrasound appearance of a variety of intrascrotal disease processes has been described. ${ }^{6}$ No such confusion of diagnosis applies to the spectacular appearance and explosive clinical course of Fournier's gangrene, where the pain is associated with a rapidly spreading gangrene of the scrotal skin caused by a mixture of aerobic and anaerobic organisms. With prompt antibiotice therapy most cases can be arrested, but subsequent debridement and surgical reconstruction of the scrotum is generally necessary.

Scrotal trauma, if severe, may cause a testicular or scrotal haematoma. If there is a question of testicular $\frac{\bar{s}}{\stackrel{5}{ }}$ rupture, the scrotum should be explored, debrided and $\stackrel{\mathbb{Q}}{\mathscr{Q}}$ the tunica repaired. Signs of considerable scrotalo injury with a history of minor trauma should alert theclinician to the possibility of an underlying testicular ${ }_{-}^{\circ}$ tumour. Scrotal pain, swelling and bruising with $\vec{\omega}$ passage of blood from the urethra and an inability too pass urine all suggest the possiblity of a urethralo rupture.

The causes of scrotal pain so far described have allo been associated with obvious clinical pathological -

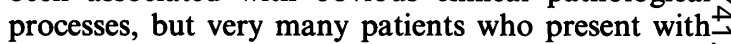
such pain have no immediately obvious intrascrotali pathology. In such cases a careful examination of the ${ }^{-}$ surface of the testis and epididymis may reveal a을 localized tender nodule on the surface of the testis. Onultrasound scanning the nodule can be seen to cause anc acoustic shadow and at scrotal exploration a localized ${ }^{2}$ area of nodular peri-orchitis may be encountere ${ }^{7} \overrightarrow{\mathrm{D}}$ This is a common condition, a result of an inflamm tion within the vaginal space, leading to a chromico hypertrophic serositis, characterized by collagenouss thickening and nodularity of the tunica vaginalis. These areas generally become less tender and mayoे separate from the tunica to become loose bodies in theo vaginal space. They need not be removed.

Where pain is associated with the testis being drawn을 up to the external inguinal ring, cremasteric spasm is the likely cause. This may be relieved by circumcision of the cremaster and therefore division of the genitofemoral nerve. Many young men with scrotal pain have no more to find than a tender and prominent: epididymis. These men may be reassured, their pain 3 . possibly being caused by seminal congestion. If as persistent ache is described within the body of the 3 testis an ultrasound examination should be performed to exclude a small impalpable central testicular? tumour. Scrotal pain with no obvious cause may rarelyo precede the eruption of the vesicles of herpes zoster. More often, when both local causes and the possibilityo of referred pain have been excluded, no immediaten explanation for the pain can be given and the patientr will be best served by a frank explanation that no ${ }_{0}^{\mathrm{O}}$ serious cause for the pain exists. 


\section{References}

1. Watanakunakorn, C. Staphylococcus aureus endocarditis presenting as acute scrotal pain. Postgrad Med J 1987, 63: 585-586.

2. Chapman, R.H. \& Walton, A.J. Torsion of the testis and its appendages. $\mathrm{Br} \mathrm{Med} J$ 1972, 1: 164-166.

3. Mittemeyer, B., Lennox, K.W. \& Borski, A.A. Epididymitis: A review of 610 cases. J Urol 1966, 95: 390-392.

4. Schiebel, J.H., Anderson, J.T., Brandenhoff, P. et al. Chlamydia trachomatis in acute epididymitis. Scand $J$
Urol Nephrol 1983, 17: 47-50.

5. Lapides, J., Ajemian, E.P., Stewart, B.H., Breakey, B.A. \& Lichtwardt, J.R. Further observations on the kinetics of the urethrovesical sphincter. J Urol 1960, 84: 86-94.

6. Scott, R.F., Bayliss, A.P., Calder, J.F. \& Carvie, W.H.H. Indications for ultrasound in the evaluation of the pathological scrotum. Br J Urol 1986, 58: 178-182.

7. Morgan, A.D. Inflammations of the tunica vaginalis. In Pugh, R.C.B. (ed) Pathology of the Testis. Blackwell Scientific Publications, Oxford, 1976, pp. 120-127. 